\title{
Mental Health Act reform
}

\section{Should psychiatrists go on being responsible?}

\author{
Trevor Turner, Mark Salter and Martin Deahl
}

Psychiatrists have been complaining about mental health legislation for over a century (Smith. 1891), usually in terms of the delays engendered, paperwork and bureaucracy, and the impositions on clinical practice. As a result they have gained more powers, and perhaps much-needed status within the medical profession, to the concern of some commentators (e.g. Fennell, 1996). Thus, the 'triumph of legalism' (Jones, 1993) of the Lunacy Act 1890 was modified by the Mental Treatment Act 1930, whereby outpatients and voluntary patients were encouraged and 'asylums' became 'mental hospitals'. Then came the radical change of the Mental Health Act (MHA) 1959, making compulsory detention an essentially medical decision and removing the routine of the courts, but retaining a theme of requiring 'treatment in hospital'. The Mental Health Act 1983, however, was a touch antimedical, since it strengthened the role of the approved social worker (ASW) and enhanced the importance of a patient's consent to treatment. "The primacy of the medical model and the paramountcy of the psychiatrist are certainly subject to greater limitations and external review", was the opinion of William Bingley, then Mind's Legal Director, now Chief Executive of the Mental Health Act Commission - reviewing the Act in its early days (Bingley, 1985).

\section{Recent history}

In 1983 the Mental Health Act Commission was also established. Its remit included protecting the interests of detained patients, reviewing the MHA in general, providing second opinions, and preparing a code of practice. Its first report, however, admitted that one of its most difficult tasks was the problem of giving compulsory treatment to patients on leave in the community and it was suggested that it should be given the power "to investigate why patients are not in hospital" (Hamilton, 1986). The tragic killing of Isobel Schwarz, a social worker, by Sharon Campbell in 1984, and the increasing range of community care scandals, as documented by the award-winning Times journalist, Marjory
Wallace (Wallace, 1986), underlay increasing concerns as to mental health policy.

The Regina $v$. Hallstrom ex parte W. (1986) case in 1985 (making illegal the practice of admitting Section 3 patients overnight so as to renew and extend their leave) exemplified the central dilemma, which has become a focus of discussion over the last decade. Namely, should we introduce a community treatment order (CTO) - as in Australia (Hambridge \& Watt, 1995) - so as to protect patients from relapsing. or should we continue to give preference to patient choice, regardless of the consequences? Improved community supervision has been the aspiration of numerous inquiries, such as the now iconic report concerning Christopher Clunis (Ritchie et al, 1994), and these have become the major information source for the public as to how mental health care is (and is not) working. In particular the existing laws on mental health are now seen as out of date even by the responsible Secretary of State (Department of Health. 1998a), despite clumsy and arguably ineffective addenda. These include the 1994 Supervision Register (strongly opposed and irregularly used; Caldicott, 1994: Vaughan, 1996), and the Supervised Discharge Order, arising from the Mental Health (Patients in the Community) Act 1995, which is little more than an embellished guardianship order, considered even to be "antitherapeutic" (Eastman, 1995).

The various problems of the MHA have been well-documented although there has been little research to inform the debate. Thus Ung (1993) found considerable confusion as to the independent' nature of the second medical recommendation (for Section 2 or 3), while Sammut \& Sergeant (1993) showed little difference in outcome whether or not patients were hospitalised, particularly when there were disagreements between psychiatrists and social workers. However, Rusius (1992) found that two-thirds of patients were 'grateful' for being forced to stay in hospital, and 60\% were (post-treatment) grateful for having been given medication against their will. Whether that finding would extend to the current problems of, for example, the inner city areas, with their high rates of compulsory admission, comorbidity with drug misuse and 
violent episodes, is not known. The attitude of politicians, towards their own MHA legislation, is perhaps best revealed by Section 141 of the current Act. This states that the Speaker has to be notified if a member of parliament is detained, so as to ensure that he or she is visited and examined by two specially chosen doctors, and by the President of the Royal College of Psychiatrists. Our own legislators want, automatically, a second and a third opinion.

\section{Current problems of the MHA 1983 Escalation of 'sectioning'}

The use of the MHA is increasing, from some 15000 to over 25000 formal admissions between 1987-98 and 1997-98 - both nationwide and locally (Department of Health, 1998b), and across most areas of the Act. As can be seen in Table 1, our own sector (City \& Hackney, population approximately 200000) has more than trebled the total number of compulsory admissions under the MHA, with particular increases over the last six years in the civil Sections 2, 3 and 4 rather than court or police generated admissions. Since between 60 and $70 \%$ of admissions are readmissions, these figures illustrate the difficulty of maintaining treatment for those discharged into the community.

It is of note that this has occurred in spite of an increased commitment by the East London and City Health Authority to community care, in terms of staff and funding. The current jointly managed community teams (combining health and social service workers) were in fact praised by the district audit for targeting those with higher levels of need in terms of the Care Programme Approach (CPA). Yet the impact of CPA, risk management and the concern about untoward incidents may well have contributed significantly to these figures. A major fear of the 1998 Bournewood case ruling (L. $v$. Bournewood Community and Mental Health Trust ex parte L. 1998) (thankfully overturned by the House of Lords) was that thousands of otherwise informal patients would require detention, involving

Table 1. Formal admissions under the Mental Health Act 1983, City \& Hackney District/Trust, from 1984-1996

\begin{tabular}{lccc}
\hline Type of Section & 1984 & 1990 & 1996 \\
\hline Court initiated (e.g. S37/41) & 81 & 50 & 59 \\
136 & 65 & 96 & 60 \\
5.2 & 56 & 92 & 147 \\
$2 / 3 / 4$ & 99 & 227 & 496 \\
Totals & 228 & 465 & 762 \\
\hline
\end{tabular}

1. No medium (or intensive) secure unit on site. major costs in terms of administration and review.

\section{Climate of 'untowardness'}

The rising number of formal inquiries into untoward incidents - as formalised in 1994 by the procedure outlined by the Government order HSG(94)27 - has been well-documented by the Zito Trust (Sheppard, 1995) and the impact of these on participating psychiatrists has also been discussed. A significant number of untoward incidents are generated by patients who have been discharged from hospital, on occasions even by tribunals or MHA managers, and the great majority have had previous Section Orders. The public and Government perception is very much that community care is failing (The Independent, 7 March 1996; Department of Health, 1998a), as seen in the light of these incidents, with demands that more people are kept in hospital. The remorseless rise in the number of medium secure unit beds illustrates this process, a kind of creeping forensic asylumisation.

\section{Legislative inflexibility}

At present Mental Health Review Tribunals (MHRTs), and Hospital Managers' hearings, are only empowered to discharge patients or not to discharge patients, although decisions can be deferred. There is no continuing responsibility attached to those who make these decisions, the psychiatrist continuing to be the responsible medical officer (RMO). Even a MHRT Chairman (Wood, 1998) has admitted that "it is most probable that the juxtaposition of semi-formal Managers' Reviews and Tribunal Hearings is excessive - it can certainly lead to confusion". He also concedes that "the current pattern of the availability of Tribunals is not ideal". While vital for patients' rights, these arrangements are bound, over time, to reflect the difficulties of power without responsibility.

The bugbear of current legislation is that one can only ensure treatment for patients lacking insight by requiring that they receive treatment in hospital'. Psychiatric units certainly have expertise in terms of nursing, assessment, containment and rehabilitation, but as often as not the problematic patient - in order to remain well-primarily needs regular medication. In truth compulsory depot medication is often the only reliable, and effective, option. The quandary for the psychiatric team, when faced with the deteriorating patient not yet ill enough to require treatment in hospital, is well outlined in The Falling Shadow (Blom-Cooper et al, 1995) about which the Mental Health Act Commission (1997) has recently circulated a discussion document. 
Thus, a change in presentation, with an established history of dangerous behaviour, may be considered sufficient to initiate at least a Section 2 order. But this approach assumes previous knowledge that may not be the case among transient populations.

\section{Morale}

Reflecting all of these concerns is the morale of today's psychiatrists, whether general or specialised (Deahl \& Turner, 1997). Although trained as doctors, they are being asked to be "community supervisors', whatever that means. Formal risk management assessments, of each and every patient, would suggest that we need to rebuild the asylums, but resources, hospital managers and the limitations of Section 17 of the MHA insist on discharge. Either way the responsible psychiatrist and mental health team are always in the firing line, and readily deemed irresponsible by the public or illiberal by the patient/ service user.

\section{Possible solutions}

British psychiatrists are unaware that their dilemmas are viewed with perplexity by colleagues on the continent. In Belgium. Spain or Germany the courts decide if someone requires treatment. Recent violent assaults on two leading German politicians (Oscar Lafontaine, the Finance Minister, and Wolfgang Schäuble, a leading conservative, now in a wheelchair) by patients with psychosis led to no significant backlash against the psychiatric community, and minimal changes in attitudes towards mental illness (Angermeyer \& Matschinger, 1996).

Psychiatrists treat people, but it is not their job to be responsible for individual citizens' behaviour in the community, which is an issue of civil liberties and a matter for the courts and statutory authorities. There is a clear separation of the therapeutic from the supervisory. Such conditions used to pertain in this country prior to 1959 , but were changed because of concerns as to excessive legalism.

Any reversion thereto will need to address these concerns, but the 40 years since 1959 have shown a rise in medical legalism anyway, in terms of appeal processes, hearings, paperwork and additional legislation (e.g. the Supervised Discharge Order). Psychiatrists now have the worst of both worlds, being in the front line of civil concern (where the courts and police perhaps should be) yet not having the quid pro quo of a speedier or more therapeutic process.

If it is considered that psychiatrists should no longer take on the burden of being both doctor and civil supervisor, then one has to consider how a revised system could operate. We would suggest that reversion to the courts, or an enhanced role for MHRTs, would be one way forward. Thus, instead of MHRTs only being empowered to discharge patients, they should in fact routinely review all patients detained under the MHA. As well as powers of discharge. they would be empowered (as with current Section 41 procedures) to extend leave, to attach conditions to that leave (e.g. medication, CPA arrangements, guardianship, control over money) and to review patients on a continuing basis.

The role of the hospital managers, currently out of date and extremely unfair given the kind of pressures managers are put under (by patients and psychiatrists), could be taken over by the Mental Health Act Commission in terms of reviewing quality of care as well as documentation, patients' complaints and other day to day issues of the therapeutic environment. If tribunals were thus empowered, it would be possible to consider the simplification of the MHA to incorporate a routine emergency (i.e. current Section 4) or assessment (i.e. Section 2) order, with all other treatment or extended orders being decided by tribunal. The psychiatrist and the mental health team would revert then to their appropriate roles of care and treatment, and advice about treatment, rather than the oxymoronic task of community supervision.

In such a scenario we should also consider disposing of the notion of the RMO and the role of the ASW. While it is reasonable that one (or two) doctors should be involved in the initial assessment of patients, it should be possible given appropriate training for a wide range of other professionals, or even non-professionals, to apply for detention. The ASW was promoted in 1983 in order to relieve the patient's nearest relative of responsibility, but the ASW is now also being asked to deliver continuing care via the $\mathrm{CPA}$, in a range of complex, financially related and sometimes therapeutic processes. Would it not be reasonable for anyone who has a bona fide interest in the patient (and this can easily be established in terms of the tribunal review) to be able to apply for a Section? This is currently the case in New Zealand, and has worked effectively. Close friends, community policemen, community nurses, can all make the application, as can the social worker, thus making it possible to respond flexibly to an individual patient, whether faced with a first onset illness or a current deteriorating patient scenario. This would enhance the generic, community team approach, while taking away the potential for scapegoating individuals. Psychiatrists, nurses and ASWs should have therapeutic responsibilities outwith the control of civil liberties. 


\section{Conclusion}

Revising the Mental Health Act must be looked at in the light of history, current practice elsewhere, recent legislative difficulties (e.g. Bournewood), and the practicalities of current psychiatric treatments. A new Act must reflect the major changes in treatment, philosophy and practice over the last 40 years. The MHA 1983 is outdated in terms of language and concept, and fails to address the central role of medication in delivering community-based treatment. It has many practical strengths, in terms of plain language and broad definitions, but the modern emphasis on rights over responsibilities has paradoxically turned the notion of the responsible into the notion of the blameworthy. The wider debate about informed consent, the increasing role of the courts in treatment decisions of modern medicine, and the admirable rise in the users rights movement (in itself a tribute to the quality of psychiatric treatment) all need addressing. In such a climate statutory bodies, such as courts or tribunals, should decide on compulsion while mental health specialists decide on treatment. Routine tribunals for all, simplified initial procedures, judicially supervised continuing care and treatment, and a review of the notion of the RMO should be the basis for MHA reform.

\section{References}

ANGerMEYER, M. C. \& MATSCHInger, H. (1996) The effect of violent attacks by schizophrenic persons on the attitude of the public towards the mentally ill. Social Sclence and Medicine, 2, 1721-1728.

BingLEY, W. (1985) The Mental Health Act 1983 - how is it working? Journal of the Medical Defence Union, 1.9-10.

BLOM-COOPER, L., HALEY, H. \& MURPHY, E. (1995) The Falling Shadow: One Patient's Mental Health Care 1978-1993. London: Duckworth.

CaldicotT, F. (1994) Supervision registers: the College's response. Psychiatric Bulletin, 18, 385-386.

DEAHL, M. \& TURNER, T. (1997) General psychiatry in noman's land. British Joumal of Psychiatry, 171, 6-8.

DEPARTMENT OF HEALTH (1998a) Modernising Mental Health Services: Safe, Sound and Supportive. HSC 1998/ 233:LAC(98)25. London: Department of Health.

- (1998b) In-patients Formally Detained in Hospitals Under the Mental Health Act 1983 and Other Legislation. England: 1987-88 and 1992-93 to 1997-98. Bulletin 1998/34. London: Department of Health.
EASTMAN, N. (1995) Anti-therapeutic community mental health law. British Medical Joumal, 310, 1081-1082.

FENNELL. P. (1996) Treatment Without Consent. London \& New York: Routledge.

HAMBRIDGE, J. \& WATT, N. (1995) Involuntary community treatment in New South Wales, Australia. Psychiatric Bulletin, 19, 45-47.

Hamilton, J. R. (1986) The Mental Health Act Commission. Brittsh Medical Joumal, 282, 849-850.

JONES, K. (1993) Asylum and After. London: Athlone Press. MENTAL HEALTH ACT COMMSSION (1997) The Falling Shadow Report and the Deteriorating Pattent - Legal and Ethical Special Interest Group Discussion Paper. Nottingham: Mental Health Act Commission.

RTCHIE, J. H., Dick, D. \& LINGHAM, R. (1994) The Report of the Inquiry into the Care and Treatment of Christopher Clunis. London: HMSO.

Rusrus, C. W. (1992) The Mental Health Act 1983 - what does the patient think? Psychiatric Bulletin, 16. 268-269.

Sammut, R. G. \& Sergeant, H. (1993) Disagreements between psychiatrists and soctal workers over compulsory admissions under the 1983 Mental Health Act. Psychiatric Bulletin, 17, 462-465.

SHEPPARD, D. (1995) Learning the Lessons. London: Zito Trust.

SMrTH, P. P. (1891) Defects in the working of the Lunacy Act 1890. Journal of Mental Sclence. 37, 61-75.

UNG, E. K. (1993) Who should act as the second medical recommendation for Section 2 and 3 of the Mental Health Act? Psychiatric Bulletin, 17, 466-468.

Vaughan, P. J. (1996) The Supervision Register: one year on. Psychiatric Bulletin, 20, 143-145.

WALACE. M. (1986) A caring community? The plight of Britain's mentally ill. Sunday Times Magazine, 3 May. 25-38.

WOOD, SIR J. (1998) What I expect of my psychiatrist: the mental health review tribunal. Advances in Psychiatric Treatment, 4, 197-201.

L. v. Bournewood CommuntTy and MENTAL Health TRUST ex parte L. (1998) I All ER, 634.

REGINA $v$. HALLSTROM ex parte W. (1986) QB 109d.

Trevor Turner, Consultant Psychiatrist and Clinical Director of Research and Development, Martin Deahl, Consultant Psychiatrist and Director of Postgraduate Education, and Mark Salter, Consultant Psychiatrist, Department of Psychiatry, East Wing, Homerton Hospital, Homerton Row, London E9 6SR 